\title{
Exploration and Practice of Furniture Engineering Talents Training: Perspective of Emerging Engineering Education
}

\author{
Huajie Shen \\ Material Science and Engineering School \\ Southwest Forestry University \\ Kunming, China \\ huajieshen@hotmail.com
}

\author{
Jian Qiu \\ Material Science and Engineering School \\ Southwest Forestry University \\ Kunming, China \\ qiujianswfu@foxmail.com
}

\begin{abstract}
To improve students' comprehensive engineering ability is the core content of the quality of personnel training in industrial universities, with the outbreak of Emerging Engineering Education. Under the guidance of $3 E$, combined with the social demand characteristics of Furniture Engineering talents, this paper takes Southwest Forestry University as a case study object and adopts "three-dimensional three-section" training model, and explores the compound to set up the framework of personnel training. We try to explore the cultivation of five abilities such as personal efficacy, knowledge ability, academic ability, technical ability and social ability through independent learning, seminars, research participation, engineering intervention, school-enterprise cooperation and other methods, In order to make it molded in the five aspects of humanities, science and technology, intellectual + practice, professionalism and ecological outlook. The study suggests that the ecological concept should be blended in the cultivation of the other four aspects. At the same time, Internet + Education has more connection points needed to be further studied, such as the development of smart teaching tools.
\end{abstract}

Keywords-Emerging Engineering Education;Furniture Engineering ;Talent Development;Complex; Ecological Concept

\section{INTRODUCTION}

Recently, there has been a lot of discussion about the growth and contribution of New Youth under the times of New Era. It has raised the educational circles thinking on 3E's education science and triggered the training of $3 \mathrm{E}$ talents in industrial universities ${ }^{[1]}$. As one of typical industrial universities $^{[2]}$, Forestry Universities (FU) are commonly forming an accumulation of engineering talents with the development of forestry-related disciplines and non-forestry disciplines $^{[3]}$. As one of the characteristics of forestry disciplines, Forestry Engineering mainly engages in wood processing and utilization, furniture design and manufacturing engineering talents. Due to the closely the needs of social talents, different university enjoys its special and meaningful highlights on personnel training of Furniture Engineering (FE), such as school-enterprise cooperation training ${ }^{[4]}$, schoolenterprise collaborative innovation center $^{[5]}$, international cooperation $^{[6]}$, basic-field training ${ }^{[6]}$, excellent-engineer talent program $^{[7]}$, mentor system ${ }^{[8]}$, order form ${ }^{[4]}$ and so on. However,

Sponsors- National Engineering Master's Degree in Postgraduate Education Online Curriculum Major Construction Project "Furniture Design and Manufacturing". it is worth discussing how to meet the needs of $3 \mathrm{E}$ and to keep pace with the times in the training of FE talents.

\section{RESEARCH STATUS OF 3E TALENTS TRAINING OF FE}

\section{A. 3E Talents Training in IU}

Recently, there has been much discussion about what is the kernel of $3 \mathrm{E}^{[9]}$. Lin $\mathrm{Jian}^{[10]}$ defined the connotation and characteristics of it, supposed that the talents are of highquality composite and strong-engineering practice ability, and of strong innovation ability with international competitiveness $^{[11]}$, which were similar to Hu Bo's objectives ${ }^{[12]}$. Wu Aihua ${ }^{[13]}$ elaborated on the ways to innovate the personnel training mechanism for engineering and the measures to establish a safeguard system. Li Qiquan ${ }^{[14]}$ studied the construction of engineering culture education system from the four-dimensional perspective of engineering culture base, engineering culture course, engineering culture environment and engineering culture research. Based on the basic characteristics of new industries and the new requirements for engineering talents, Shi Xiaoqiu ${ }^{[15]}$ analyzed the incommensurability between the existing engineering education system in local colleges and new industries and new demands. Zou Xiaodong ${ }^{[16]}$ held that "integration of science and education" should be one of the effective ways to cultivate 3E personnel under the new normal of running a university. Lu Guodong $^{[17]}$ thought the construction of new projects must focus on training engineering innovation and adapt to change in two capacities. Zhou ${ }^{[18]}$ considered that adopting the topdown and bottom-up synergistic interaction is the best way to reform the $3 \mathrm{E}$ education. Zhang Haisheng ${ }^{[19]}$ argues that the transformation of higher education through cross-border education must insist on the transition from subject situations to application situations, problem-based settings and social needs. Cha Jianzhong ${ }^{[20]}$ studied the commonalities of workplace situations and other issues and studied the cultivation of engineering talents. Gong Xiaojia ${ }^{[21]}$ combined with practical experience to explore the teaching of new engineering personnel training.

Those studies focus on the universality of colleges and universities and focus on the concepts, connotation, curriculum 
system, social needs and model differences. In terms of cultivating $3 \mathrm{E}$ talents in IU, Lin Jian ${ }^{[10]}$ close ties with industry and industry advantages, focusing on training Compound Talents (CTs).

\section{B. 3E Talent-training in FE}

Many researches were poured timely into the training models of $\mathrm{FU}^{[3,22-26]}$, although less involved in the topic of 3E. In the field of personnel training of FE, the task is to be characterized by leading, blending, innovative, cross-bordered and development. The CTs is in line with talent diversified demand of new technologies, new industries and New Economy. More or less, most of FUs have the corners that the talents training and the employment demand can hardly be seamlessly connected, and the employees need to spend extra cost to reserve the talents. Additionally, it is not so ideal of the talents' performance in the further scientific research or project ${ }^{[27]}$. Jiang Haixia ${ }^{[28]}$ proposed looking at the personnel training of FE from a cross-border perspective and Liu Xianbo ${ }^{[29]}$ discussed the train mode of specialized personnel training of furniture design in a particular field.

To sum up, we can see that the training of $3 \mathrm{E}$ talents in FE needs to be closely linked to the demand characteristics of talents in the future society. Based on the training of CTS talents, the feasibility of "Internet + Education" emerged technology or means were fully blend. Hence, five typical competencies such as individual potential, knowledge ability, academic ability, technical ability and social ability are supposed to be formed before the graduates come into being ready to perform their distinguished knowledge of five aspects of humanities, science and technology, intelligence and practice, professional accomplishment and ecology outlook, which are welcome by employee.

\section{3E TALENT TRAINING MODE: THREE-DIMENSIONAL THREE-SECTION MODEL}

In exploring students' ability of cultivating comprehensive 3E skills, drawing on Hall's three-dimensional structural model [30], combined with the actuality of furniture engineering personnel training and the summary of five abilities and five aspects, we can seize the three dimensions of Time, Space, and Knowledge, and can rebuild up a new three-dimensional training model focus on, as shown in fig.1. Through reading the figure, according to the learning stage in the time dimension, the talent training dimension guide by Time is divided into three important periods of guide period, perfect period and sublimation period. At the same time consider the various knowledge or skills required completing each stage, we could touch the forming of Knowledge dimension. From a shallow, deep, complex and paradigm-based paradigm, the Space dimension could be translated into: focus on future needs and occupations, and mainly cover three aspects of national strategy, industry demand, and future development.

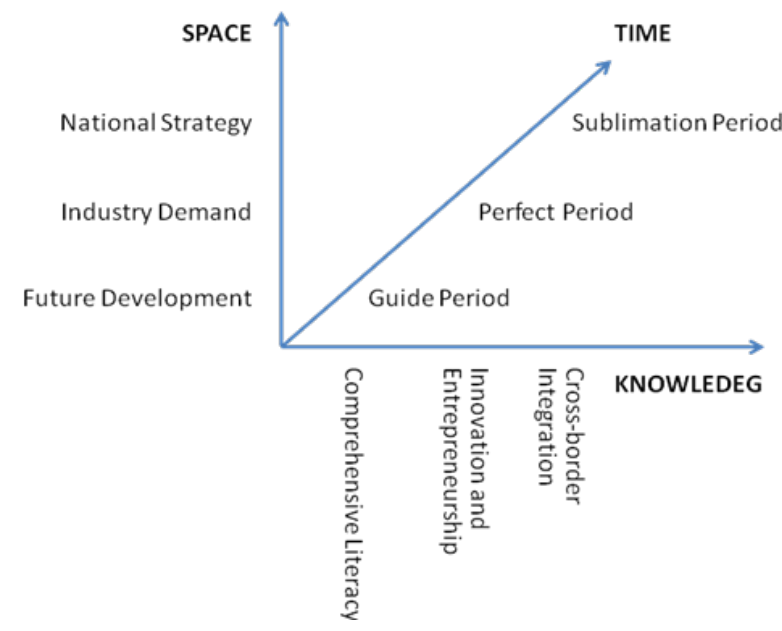

Fig. 1. Three-Dimensional Three-Section Model

\section{PRACTICAL EXPlORATION OF 3E TALENT IN FE}

It can be seen from the above that the cultivation of compound talents mainly needs to be harvested qualitatively in five capacities and five aspects. All aspects of access are not isolated. Among them, the ecology outlook runs through the process of forming the other four aspects in a way that integrates ethics, values, attitudes, behaviors and global awareness. We should systematically and comprehensively carry out the $3 \mathrm{E}$ talent training of FE with a view to closely connecting with classroom teaching and broadening the ways of using our spare time. Through our practice, we examined different modus, such as independent study, seminars, research projects, engineering interventions, cooperation between schools and enterprises, etc. These Methods were developed by using some means that known as second classroom, hot-topic discussion, Internet+, CDIO training, internship practice and other means to explore and practice, which could be read in Fig.2. What is more, many means often vary from a FU to another FU, and there are many sub-means that easily penetrate into various methods.

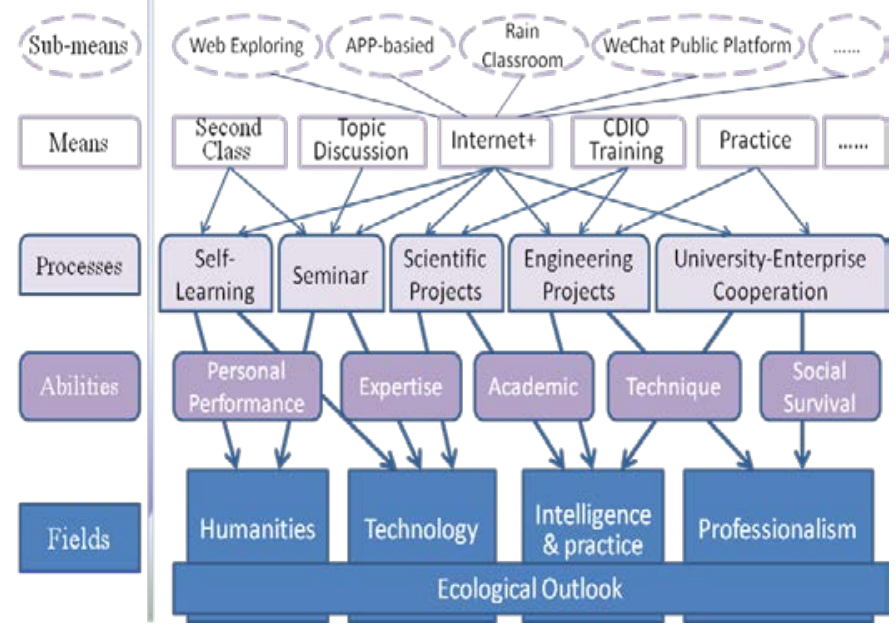

Fig. 2. Schematic of CTs in FE 


\section{A. The second class-based Self-Learning}

Self-Learning extends the normal class learning, but also trains the formation and improvement of individual performance, thus it is almost helpful to improve students' skill and knowledge in humanities and social sciences literacy. In the implementation, Self-Learning appropriates to the means of the second classroom, combines with the any suitable submeans related to Internet + . Take the practice of Southwest Forestry University (SWFU) for instance, we adopted the submeans of APP-application and adopted the access of Xuetangzaixian APP, developed by a famous online education and training company in Beijing, China. On the one hand, we took the form of extra-curricular interest groups to carry out the turn-to-turn theme exchange. Students grouped freely, checked the relevant information, carried out their discussion, and displayed their subjects of the discussion. Certainly, at the end of every exploration, we concluded each process as tutor. Read from the feedback we sought, students had broadened the path of enhancing their overall literacy, increased the spirit of solidarity and mutual assistance, strengthened their ability to integrate disciplines, and tapped the potential of practical operation.

On the other hand, based on the employment complex of past graduates such as Hometown Po, a series of activities such as thematic debates and alumni talks were held to enhance students' understanding of the furniture industry, their understanding of regional development and their understanding of innovation and entrepreneurship.

\section{B. Seminar focus on Topic Discussion}

Seminar-learning is benefit for students to gain professional knowledge, being supplemented by humanities training, and is popular with college students. Seminar [27] as a well-known teaching system has been perfected in the regional teaching practice with higher quality of education system such as Japan, South Korea and the United States. In the teaching practice of several lessons, take Furniture Materials Science, Non-wood Furniture, Ergonomics for example, we explore the topic discussion-based seminar and study methods, combining with brainstorming, Delphi process and other tools to discover the topic selection, relevance ranking, program execution and other aspects of the exploration and attempt. Among them, the Rosewood Furniture as an sample, the development of SWFU Rosewood Furniture Text Webpage was reached at, where the sub-means of web-explore war brought to combine other means hardly. According to the information feedback from students in the questionnaire, the corresponding SeminarPresentation activities were carried out to improve students' ability to perform activities so as to make their initial experience in vocational literacy.

\section{CDIO-based Training to Participate into Scientific Research}

Scientific research feeds back teaching, benefiting students to timely access to scientific research frontier dynamic information in professional fields, cultivating cells of scientific research, cultivating academic ability and accumulating achievements in scientific research and intellectual practice. Scientific research participation is a reflection of teaching research and teaching, benefiting students to personally discover the points of interest in the participation and implementation of research projects.

Conceiving-Designing-Implementing-Operation (CDIO) is the result of extensive consensus on international engineering education reform in recent years. In the course of scientific research, we explored the intervention of CDIO training. In the field of wood science research, we combined the inspiration of Internet + and developed a website application based on "Inside Wood", of which ours is optimized ${ }^{[31]}$. It is a meaningful guide for talents to integrate knowledge, to use knowledge to solve the problem.

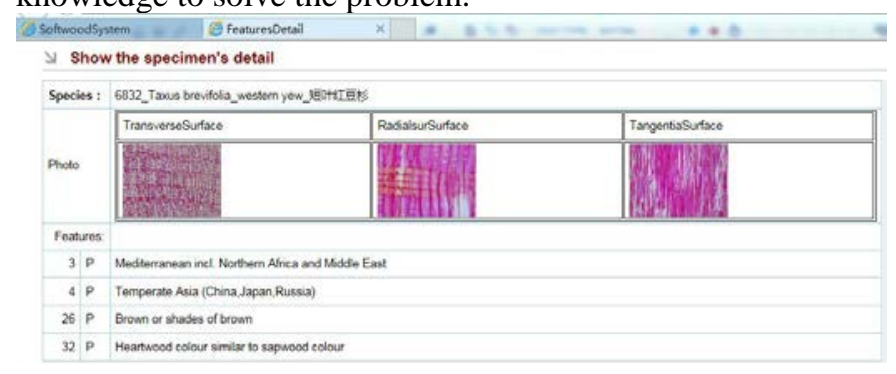

Fig. 3. Web development based on Inside Wood

\section{Engineering Intervention and University-Enterprise Cooperation}

Engineering Intervention methods and UniversityEnterprise Cooperation are mainly by means of practice linked to theoretical courses correspondingly. In practice, on the one hand, it is necessary to construct a comprehensive experimental and practical teaching system through the ways of reasonably revising experimental teaching contents, optimizing engineering application projects, training innovation and entrepreneurship projects, participating in competitions such as design competitions, and so on. On the other hand, the difference should be adopted at different levels of teaching and ability training, by exploring the different levels of teaching methods to form distinctive characteristics of experimental teaching mode.

1) Engineering Intervention: Engineering intervention mainly refers to guiding students to participate in or implementation of science and technology innovation or professional events and other topics targeted project management philosophy. For example, innovative and entrepreneurial projects that guide students in implementing science and technology innovation in undergraduates are involved in engineering management thinking. When guiding students to conduct professional academic skills competitions or designing project competitions, the process of participation is strengthened with emphasis on participation to enable students to participate in the project. Lastly, the normative aspects of implementation have been raised. In addition, during the summer special practice of Jinggang EmotionChina Dream, which guided all the students in the past, focusing on practical issues and emphasizing engineering field 
of vision training.We hence focused on the humanities and social sciences where ther talents were turned out to enjoy.

2) University-Enterprise Cooperation: The cooperation between universities and enterprises is to give full play to the potential of colleges and enterprises to complement each other's strengths and to focus on market-based exploration of research projects in the form of cooperation or order-type training of personnel training. At present, there are some teaching content of talent training has lagged behind the development of today's furniture industry in the business practice, simulation teaching there are deficiencies. This will directly affect the talent's understanding of the workplace scenario and the acquisition of forward-looking knowledge of the industry, making it difficult to form a comprehensive thinking that can solve the actual production problems. Deepseated engineering intervention and school-enterprise cooperation methods will play an important supporting role in the practical education system of personnel training. In the course of implementation, we should give play to the advantages of both parties in personnel training, namely, the capital, production technology and equipment of enterprises, rich experience in practical operation, the profound theoretical knowledge in colleges and universities, rigorous teaching methods and methods, and open academic horizons Construction practice base, excellent engineer training base, comprehensive training base for engineering education, etc., to launch a full range of scientific research cooperation or practical cooperation.

\section{CONCLUSION}

Furniture Engineering Talents' Training is one of the important ways to cultivate talent in forestry engineering discipline. Under the field of $3 \mathrm{E}$, this paper explores the means of "Internet + Education". Through our practice, we touched deeply of the special significant pragmatic utility in the training of undergraduates' personnel, and had five students' personal efficacy, knowledge ability, academic ability, technical ability and social ability were being improved clearly. Therefore, five aspects most the talents could form are commonly focused on ecological outlook, which one links the other four known as humanities, science and technology, intelligence, and professionalism. The cultivation of competence has its own focus, the means it depends on are not the same, and the available aspects also have their own advantages. In the author's exploration in the past two years, "Internet $+"$ has more practical links with teaching, such as the development of intelligent teaching tools.

\section{ACKNOWLEDGMENT}

We would like to express our positive love to Yunnan Provincial Department of Education who provided a meaningful chance for us to learn in the name of visiting scholars in Center of Wood Anatomy Research (CWAR), a world-known research center belonged to United States Department of Agriculture. Also we would like to pour our full emotion to thanks the benefit that shared by Alex C.
Wiedenhoeft, team leader of CWAR, and to thanks the idea exchanges shared by his group.

\section{REFERENCES}

[1] Boudreau, Kristin. "To see the world anew: learning engineering through a humanistic lens." Engineering Studies, vol. 7(2-3), pp. 206$208,2015$.

[2] Zhao Zhe. "Thoughts on the Planning and Development of Twelve Five - Year Plan after Local Colleges and Universities Transfer to Local Colleges and Universities." Journal of Higher Education Management, vol 5(1). Pp. 18-23,2011.

[3] Liao Xiaoping."Forestry Colleges and Universities Should Coordinate the Relationship between Forestry-related Discipline and Non-forest Discipline - A Case Study of Central South University of Forestry and Technology." China Agricultural Education, vol 1. pp. 6-10.2017.

[4] Hu Chuanshuang, Yun Hong, Wang Ting, Li Kaifu. "Reform and Practice of Undergraduate Training Mode of Wood Science and Engineering in South China Agricultural University." Forestry Education in China, vol 30(2). pp. 13-16. 2012.

[5] Wu Lingrong, Meng Xiaoke. "Study on Construction of College Students Practice Training Base - A Case Study of Furniture and Industrial Design School of Nanjing Forestry University." Technology of Enterprise Technology, vol 33 (31). pp. 81-82 + 95. 2014.

[6] Hua-Jie Shen, Jian Qiu, Han Liu. Some views on developing furniture industry in Yunnan under the background of Internet plus. 2nd Annual International Conference on Social Science and Contemporary Humanity Development. Wuhan, Hubei, China, July 15-17, 2016.

[7] Gu Yanting, Xu Wei. "Exploring a New Mode of Training Furniture Professionals in China - Taking Liang Xi Furniture Excellence Class of Nanjing Forestry University as an Example. " Science People (Science Education), vol 11. pp. 131-132. 2012.

[8] Zhang Jijuan, Chen Mengyao, Zhang Zhongfeng. "Research on the Cultivation of Scientific Research and Innovation Ability of Furniture and Interior Design Engineering Graduate Students. " Hunan Packaging. vol 31(03). pp. 89-91. 2016.

[9] Wang Qinghuan. "Where is New Engineering? " Guangming Daily, 2017-04-03. p. 5.

[10] Lin Jian. "Future Chinese Engineering Construction. " Tsinghua Journal of Education, vol 2. pp. 26-35. 2017.

[11] Lin Jian. "Cultivation of excellent engineers' innovative ability. " Research in Higher Education of Engineering, vol 5. pp.1-17. 2012.

[12] Hu Bo, Feng Hui, Han Weili, Xu Lei. "Speeding up New Engineering Construction and Promoting Reform and Innovation of Engineering Education - A Summary of 'Seminar on Engineering Education Development in Comprehensive Universities'." Fudan Education Forum, vol. 15(2). pp. 20-27+2. 2017.

[13] Wu Aihua. "In-depth promotion of science and technology personnel training mechanism innovation. " Research in Higher Education of Engineering, vol 2. pp.1-6. 2014.

[14] Li Qiquan, Li Hong. "Engineering Culture Education in the Construction of New Engineering." Journal of Anhui Jianzhu University, vol. 25(4). pp. 79-82. 2017.

[15] Shi Xiaoqiu, Zhao Yan, Li Xiaokun. "Reflections on the Construction of New Engineering System in Local Colleges with Integration, Opening and Adaptation ." Research in Higher Education of Engineering, vol 4. pp.10-15. 2017.

[16] Zou Xiaodong, Han Xu, Yao Wei. "Combination of Science and Education: New Normal of Running a College ." Research in Higher Education of Engineering, vol 1. pp. 43-45. 2016.

[17] Lu Guodong, Li Tuoyu. "Reflections on the Path of New Engineering Construction and Development." Research in Higher Education of Engineering, vol 3. pp.20-26. 2017.

[18] Zhou Kaifa, Zeng Yuzhen. "Exploration of Core Competence and Teaching Model of New Engineering ." Chongqing Higher Education Research, vol 5 ( 3). pp.22-35. 2017. 
[19] Zhang Haisheng. "Cross-border Integration: Development Logic and Construction Goal of "New Engineering" under the Background of Internet +." Application-Oriented Higher Education Research, vol 2 ( 3). pp.13-18. 2017.

[20] Zha Jianzhong. "Engineering Education Reform Faced with Workplace Situation - Concurrently Discuss Supply-side Structural Reform of Human Resource Market." Research in Higher Education of Engineering, vol 2. pp. 57-71. 2017.

[21] Gong Xiaojia. "Exploration on Cultivating New Engineering Creative Talents in Practical Teaching in Comprehensive Universities ." Journal of Higher Education, vol 12. pp. 141-142. 2017.

[22] Si Jiayong, Li Lijun, Min Shuhui, Zhong Zhigang. "Construction of Training System for Applied Innovative Talents Majoring in Electromechanical Specialty in Higher Forestry Universities - Taking Central South University of Forestry and Technology as an Example." Forestry Education in China, vol 34(6). pp. 23-26. 2016.

[23] Zhou Tongjian. "Exploration of Talents Cultivation Model in Higher Forestry Colleges Based on Intersubjectivity Theory." Forestry Education in China, vol 35(3). pp. 7-12. 2017.

[24] Di Mingwei, Wei Shuangying. "Exploration on Talents Cultivation Mode of Polymer Materials and Engineering in Forestry Colleges and
Universities ." Guangdong Chemical Industry, vol 43(14). pp.261-262. 2016.

[25] Yu Zaijun. "Exploration and Practice of Applied Talents Cultivation under the Mode of Industry-University-Research - A Case Study of Furniture Design and Manufacturing in Longyan College ." Journal of Longyan University, vol 31(5). pp.85-88. 2013.

[26] Chen Zujian, Shen Jiemei, Lin Ping, Ye Cuixian, Yu Zaijun, Xie Yongqun. "Fujian Furniture Design and Engineering Development Research Report ." Straits Science, vol 31(5). pp.85-88. 2013.

[27] Shen Huajie, Liu Han, Zhang Hua, Zhang Jiayan. "On the Experiential Teaching Mode of "Furniture Drawing" Curriculum." Light Industry Science and Technology, vol 4. pp.156-157. 2015.

[28] Jiang Haixia. "Innovation and Practice of Cross - border Design of Furniture Design." Industrial Design, vol 7. pp.123-124. 2016

[29] Liu Xianbo. "New Chinese furniture design personnel training." Talent Resource Development,vol 4. pp.156-157. 2015

[30] Kiladis, George N., Chris D. Thorncroft, and Nicholas MJ Hall. "Threedimensional structure and dynamics of African easterly waves. Part I: Observations." Journal of the Atmospheric Sciences, vol 63.9. pp. 22122230.2006.

[31] Wheeler EA. "Inside Wood-A web resource for hardwood anatomy. "Iawa Journal, vol. 32(2). pp.199-211. 2011. 